\title{
AVALIAÇÃO MICROBIOLÓGICA DAS MÃOS DE MANIPULADORES DE ALIMENTOS EM CRECHES DA CIDADE DE JUAZEIRO DO NORTE, CE
}

\author{
OLIVEIRA, Natallya Santos de*; GONÇALVES, Thially Braga
}

Faculdade Leão Sampaio - Juazeiro do Norte (CE), Brasil.

Recebido em: 14/01/2015; Aceito: 22/04/2015; Publicado: 25/08/2015

\begin{abstract}
RESUMO
A alimentação é um dos fatores fundamentais para a saúde na infância, assim os manipuladores devem seguir medidas de higiene eficientes, pois as mãos é um dos principais meios de contaminação microbiológica. Este trabalho teve como objetivo a avaliação microbiológica das mãos de manipuladores de alimentos em creches da cidade de Juazeiro do Norte, CE. As amostras foram coletadas das mãos dos manipuladores com auxílio de um swab estéril umedecido em $\mathrm{NaCl}$ a $0,9 \%$ e inoculado em tubo contendo BHI. As amostras foram previamente semeadas nos seguintes meios: Ágar Sangue, Ágar EMB, Ágar Mac Conkey e Ágar Manitol Salgado, incubados por 24 horas a $37^{\circ} \mathrm{C}$. Para confirmação das espécies foi feito um repique no meio chromID ${ }^{\mathrm{TM}} \mathrm{CPS} \AA$, onde foram identificadas as espécies pelo aspecto das colônias desenvolvidas. Dos 28 manipuladores, 64,29\% apresentaram Klebsiela sp., seguido de Staphylococcus aureus com 14,29\%. A presença de Escherichia coli e Candidaalbicans foi observada em 7,14\% dos manipuladores, outros microrganismos presentes foram Proteussp.e Pseudomonas sp.em 3,57\%. Os dados mostram que todas as mãos dos manipuladores estavam contaminadas por microrganismos, assim as mãos é um importante meio de transferência de microrganismos patogênicos. Havendo uma necessidade ainda maior em programas de capacitação higiênica e que os órgãos responsáveis disponibilizem produtos para a higienização das mãos no momento da preparação dos alimentos e que fiscalizem periodicamente essas creches.
\end{abstract}

Palavras-chave: Creche, Alimentação, Manipuladores, Mãos, Microrganismos

\begin{abstract}
The feeding is one of the most importants factors to health in childhood thus the food handlers must follow effective hygiene measures because the hands are a major means of microbiological contamination. This study had as objective the microbiological evaluation of the food handlershands at daycare centres in Juazeiro do Norte, CE. The samples were collected from the hands of manipulators with the aid of a sterile swab moistened with $0.9 \% \mathrm{NaCl}$ and inoculated into a tube containing BHI. The samples were first sown in the following media: blood agar, OK, Mac Conkey agar and Mannitol Salt Agar, incubated for 24 hours at $37^{\circ} \mathrm{C}$. To confirmate the species was made a sown of the material in the chrom ID TM CPS ${ }^{\circledR}$ Agar, where the species were identified by the appearance of bacterial colonies. In a total of 28 food handlers, 64.29 $\%$ presented Klebsiella sp. in their hands, followed by Staphylococcus aureus with $14.29 \%$. The presence of Escherichia coli and Candida albicans was observed in $7.14 \%$ of the handlers. Other microorganisms were Proteus sp. and Pseudomonas sp. representing $3.57 \%$. The survey data shows that all the food handlers were contaminated by microrganisms and hands is an important means of transfer of pathogenic microrganisms. There's a greater need of doing hygienic training and the responsibles offer products for cleaning of their hands during the food preparation and that someone supervises periodically these daycare centres.
\end{abstract}

Keywords: Daycare centres, Feeding, Handlers, Hands, Microrganisms.

*Natallya Santos de Oliveira; Rua Deocleciano de Bezerra, 233. Bairro Brasília. Iguatu, Ceará. CEP: 63.500-735

Email: natallya_igt@ hotmail.com Telefone: (88) 999258647 


\section{INTRODUÇÃO}

A alimentação é um dos fatores fundamentais para a saúde na infância. Sendo de máxima importância, seguir medidas de boas práticas alimentares desde os primeiros anos de vida. Devido às crianças passarem parte de suas vidas em creches e pré-escolas é nelas em que as mesmas constroem seus hábitos alimentares (ZACCARELLI; PHILIPPI, 2005).

Manipuladores de alimentos são todas as pessoas que estão relacionadas de alguma forma com o alimento (FERREIRA, 2006). Como os manipuladores são a principal fonte de contaminação dos alimentos é de extrema importância que eles tenham conhecimentos sobre as condições higiênicas de alimentos e assim seguilas (SOUZA, 2006).

A Organização Mundial de Saúde (OMS) relata que os manipuladores são responsáveis direta ou indiretamente por até $26 \%$ dos surtos de enfermidades bacterianas veiculadas por alimentos. Mesmo os manipuladores aparentemente sadios abrigam bactérias patogênicas que podem contaminar os alimentos (ANDRADE et al., 2003).

As Doenças Transmitidas por Alimentos (DTA’s) são ocorrências clínicas conseqüentes da ingestão de alimentos que possam estar contaminados com microrganismos patogênicos, substâncias químicas, objetos lesivos ou que contenham em sua constituição substâncias naturalmente tóxicas (SILVA JR, 2007).

A lavagem das mãos é uma forma indispensável de proteger os alimentos de possíveis contaminações microbiológicas. Os patógenos transmitidos pelas mãos são na maioria originados de contaminação fecal, devido a hábitos higiênicos deficientes dos manipuladores (FERREIRA, 2006).

É preconizado que todo estabelecimento possua um manual de boas práticas de manipulação de alimentos, é por meio dele que os manipuladores terão conhecimento sobre os procedimentos, e dessa forma, conhecerão mais sobre suas funções e possíveis microrganismos alimentares patogênicos (FERREIRA, 2006).

Torna-se relevante a avaliação da presença de microrganismos patogênicos nas mãos dos manipuladores, já que estes possuem o contato direto com os alimentos que serão fornecidos as crianças, um grupo vulnerável a doenças.

O principal objetivo do presente estudo foi realizar a avaliação microbiológica das mãos de manipuladores de alimentos em creches municipais da cidade de Juazeiro do Norte, CE.

\section{METODOLOGIA}

Foram visitadas todas as creches municipais da cidade de Juazeiro do Norte, CE, totalizando 28 creches. As amostras foram obtidas através da coleta de material das mãos (palma e entre os dedos) de um manipulador de cada creche, essa coleta foi feita no momento da preparação dos alimentos. Esse material foi coletado com auxílio de $s w a b$ estéril umedecido em $\mathrm{NaCl}$ a $0,9 \%$.

Antes da coleta, os manipuladores assinaram o "Termo de Consentimento Livre e Esclarecido", em duas vias, ficando uma com o manipulador e outra com o pesquisador.

Foi aplicado um check-list para avaliação das conformidades (C) e não conformidades (NC). Este teve como finalidade analisar o nível de conhecimentos dos manipuladores a respeito da sua higiene frente à manipulação dos alimentos e adequação às boas práticas no preparo de refeições. Foram entregues folhetos explicativos que continham as formas adequadas de manipulação de alimentos e de higienização dos manipuladores. 
Após a coleta, os tubos de ensaio foram acondicionados em isopor e transportados para o laboratório de microbiologia da Faculdade Leão Sampaio, onde os swabs foram inoculados em caldo BHI (Brain Heart Infusion) e incubados por 24 horas a $37^{\circ} \mathrm{C}$ em estufa. As amostras foram estocadas em criotubos a $\pm 6^{\circ} \mathrm{C}$ (ABREU, MEDEIROS, SANTOS, 2009; MACHADO et al., 2009).

Em seguida, as amostras foram semeadas nos seguintes meios: Ágar Sangue, Ágar EMB (Eosin Methylene Blue), Ágar Mac Conkey e Ágar Manitol Salgado e incubados por 24 horas a $37^{\circ} \mathrm{C}$ em estufa.

Para confirmação das espécies foi feito um repique no meio chromID TM $\mathrm{CPS} \AA$ (Biomériex), incubado por 24 horas a $37^{\circ} \mathrm{C}$, que possibilitou a identificação das espécies baseado no aspecto e coloração das colônias desenvolvidas, seguindo as normas do fabricante.

\section{RESULTADOS E DISCUSSÃO}

Diversos agentes etiológicos são passíveis de contaminação em alimentos, podendo levar a doenças, manifestações por ação de microrganismos e suas toxinas (COSTA, 2008). No entanto, as bactérias são as maiores responsáveis pelos casos de contaminação em alimentos (SILVA, 2006).

O principal patógeno identificado nas mãos dos manipuladores de alimentos, foi Klebsiellasp., com 64,29\%, seguido de Staphylococcus aureus com 14,29\%. A presença de Escherichia coli e Candidaalbicans foi observada em $7,14 \%$ dos manipuladores, outros microrganismos presentes foram Proteussp. E
Pseudomonas sp.em 3,57\% dos manipuladores, onde estão descritos na figura 1 .

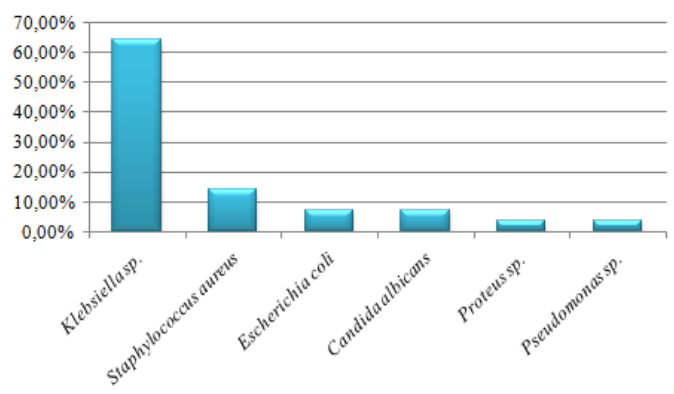

Figura 1: Principais patógenos isola dos das mãos de manipuladores de alimentos de creches municipais da cidade de Juazeiro do Norte, CE, 2013.

Como mostra os resultados acima, em todas as mãos dos manipuladores houve crescimento de microrganismos, o que mostra baixas condições higiênicas no momento da preparação dos alimentos.

Estudo mostra que Klebsiellapneumoniae, foi o microorganismo predominantemente presente nas mãos de 28 manipuladores de alguns estabelecimentos comerciais (bares, restaurantes, lanchonetes) de Araraquara, totalizando 58,3\% (LEITE; RADDI; MENDONÇA, 1989).

Klebsiella, Escherichia coli e Proteus pertencem à família Enterobacteriaceae, são amplamente distribuídos na natureza podendo ser encontrados em solos, água e materiais contaminados com fezes, mas apenas E.coli habita o trato gastrointestinal de seres humanos e animais (KONEMAN, 2001).

Dentro do gênero Staphylococcus, a espécie S.aureushabitante da microbiota normal de 30 a $50 \%$ da população mundial, é a que mais está relacionada a casos e surtos de intoxicação alimentar, pelo fato de grande parte das suas cepas produzirem enterotoxinas estafilocócicas (ZOCCHE, 2008; CHAPAVAL et al., 2009).

Foi aplicado um check-list (tabela 1) visando analisar o nível de conhecimentos dos manipuladores a respeito da sua higiene frente à 
manipulação dos alimentos e adequação às boas práticas no preparo de refeições.

Ao término das visitas às creches foi percebido que nenhum manipulador utiliza uniformes para manipular os alimentos, no entanto, foi considerado no check-list como uniforme apenas o uso do avental onde $71,43 \%$ faziam o uso deste. O mesmo aconteceu com o uso de EPI's, onde nenhum fazia o uso. Foi considerado como EPI o uso da touca, que $75 \%$ utilizam no momento da preparação dos alimentos.

Um estudo semelhante demonstrou que no momento da produção de alimentos, apenas $15 \%$ dos manipuladores faziam o uso de luvas para manipular os alimentos (CARDOSO; SOUZA; SANTOS, 2005) mostrando uma baixíssima porcentagem, o que condiz com os dados do presente artigo em que nenhum manipulador fazia o uso de luvas ao manipular os alimentos.

Foi verificado que $96,43 \%$ dos manipuladores estavam com as unhas curtas e limpas, e que $92,86 \%$ não possuíam feridas abertas nas mãos. Outro item avaliado foi se os manipuladores estavam isentos de adornos ou jóias que correspondeu $86,14 \%$.

Os manipuladores de alimentos devem ficar atentos a ferimentos nas mãos, já que a maioria das infecções purulentas de pele é causada por Staphylococcusspp ou Streptococcusspp. (SILVA; GERMANO; GERMANO, 2003).

Foi perguntado aos manipuladores se eles já haviam participado de treinamentos, cursos ou palestras sobre higienização adequada ao manipular os alimentos, regras de higiene pessoal, e 96,43\% já haviam participado, apenas um manipulador respondeu que nunca participou de nada.

A RDC 216/2004 regulamenta que os manipuladores de alimentos devem ser supervisionados e capacitados periodicamente em higiene pessoal, manipulação higiênica dos alimentos e em doenças transmitidas por alimentos (BRASIL, 2004).

O manipulador capacitado poderá garantir a qualidade da produção de alimentos, identificando perigos e tomando medidas preventivas para o controle dos alimentos (PASSARONI, 2006).

Percebeu-se que apenas $21,43 \%$ destes manipuladores exigiam que os visitantes utilizamse a touca ao entrar na cozinha da creche. A RDC 216/ 2004, estabelece que os visitantes devem cumprir os requisitos de higiene e de saúde estabelecidos para os manipuladores (BRASIL, 2004).

No que diz respeito à lavagem das mãos, $100 \%$ afirmaram que lavam as mãos com frequência e de forma correta, no entanto em todas as amostras observou-se a presença de microrganismos.

A lavagem das mãos é a principal medida para minimizar a quantidade de microrganismos e assim melhorar a segurança alimentar (RIBEIRO; REIS; ROSSI, 2000).

\begin{tabular}{|c|c|c|}
\hline & CONFORME & NÄO CONFORME \\
\hline Usam uniformes? & $71,43 \%$ & $28,57 \%$ \\
\hline Usam EPI's? & $75 \%$ & $25 \%$ \\
\hline $\begin{array}{c}\text { As unhas estão curtas e } \\
\text { limpas? }\end{array}$ & $96,43 \%$ & $3,57 \%$ \\
\hline $\begin{array}{c}\text { Possuem feridas abertas nas } \\
\text { mãos? }\end{array}$ & $92,86 \%$ & $7,14 \%$ \\
\hline Isento de adomo jóías? & $82,14 \%$ & $17,86 \%$ \\
\hline $\begin{array}{c}\text { Participaram de } \\
\text { treinamentos, cursos? }\end{array}$ & $96,43 \%$ & $3,57 \%$ \\
\hline $\begin{array}{c}\text { Os visitantes seguem as } \\
\text { mesmas regras dos } \\
\text { manipuladores? }\end{array}$ & $21,43 \%$ & $78,57 \%$ \\
\hline
\end{tabular}

\section{CONCLUSÃO}

As mãos apresentam uma importante via de transferência de microorganismos que podem ocasionar doença, dessa forma, é de extrema importância que os manipuladores tenham bons hábitos higiênicos, visando assim garantir a 
qualidade dos alimentos e proporcionar segurança alimentar às crianças das creches, grupos vulneráveis às doenças.

Os resultados do presente estudo apontam que todas as mãos dos manipuladores de alimentos estavam contaminadas por microrganismos patogênicos, o que há uma necessidade ainda maior de programas de capacitação em higiene pessoal, manipulação higiênica e conscientização com esses manipuladores.

Sugere-se também que os órgãos responsáveis disponibilizem produtos que facilitem a higienização das mãos desses manipuladores no momento da preparação dos alimentos e que fiscalizem periodicamente essas creches.

\section{REFERÊNCIAS}

ABREU, E.S; MEDEIROS, F.S; SANTOS, D.A. Análise microbiológica das mãos de manipuladores de alimentos do município de Santo André. Revista Univap, v. 17, n. 30, p. 39-57, 2011.

ANDRADE, N.J.; SILVA, R.M.M.; BRABES, K.C.S. Avaliações das condições microbiológicas em unidades de alimentação e nutrição. Ciência Agrotécnica, v. 27, n. 3, p. 590-596, 2003.

BRASIL. Agência Nacional de Vigilância Sanitária. Resolução RDC $\mathrm{n}^{\circ}$ 216, de 15 de setembro de 2004. Estabelece procedimentos de boas práticas para serviços de alimentação a fim de garantir as condições higiênico-sanitárias do alimento preparado. Diário Oficial da União, Poder Executivo, Brasília, DF, 17 setembro de 2004.

CARDOSO, R. C. V.; SOUZA, E. V. A.; SANTOS, P. Q. Unidades de alimentação e nutrição nos campi da Universidade Federal da Bahia: um estudo sob a perspectiva do alimento seguro. Revista de Nutrição, Campinas, v. 18, n. 5, p. 669-680, 2005.

CHAPAVAL, L.; AGUIAR, V.M.P.; MIRANDA, K,P.; MORORÓ, A.L.; MAGALHÃES, D.C.T. Cultura, Crescimento e Identificação de
Bactérias do Gênero Staphylococcus aureus em Leite de Cabra. Sobral, 2009.

COSTA, C.D.R.S. Importância de Staphylococcus spp. Produtores de enterotoxinas em alimentos. Monografia (Especialização) - Programa de Pós graduação em Microbiologia, Universidade de Minas Gerais, Belo Horizonte. 2008.

FERREIRA, S.M.S. Contaminação de alimentos ocasionada por manipuladores. Monografia (Especialização) - Programa de Pós Graduação em Qualidade em Alimentos, Universidade de Brasília, CET - Centro de Excelência em Turismo. 2006.

KONEMAN, E.W. Diagnóstico microbiológico: texto e atlas colorido. 5. ed. Rio de Janeiro: Medsi, 2001.

LEITE，C.Q.F.; RADDI，M.S.G.; MENDONÇA, C.P. Bactérias entéricas nas mãos de manipuladores de alimentos da cidade de Araraquara- SP. Revista Alimentar de Nutrição, v.1, p. 23-28, 1989.

MACHADO, J.R; MARSON, J.M; OLIVEIRA, A.C.S; SILVA, P.R; TERRA, A.P.S. Avaliação microbiológica das mãos e fossas nasais de manipuladores de alimentos da unidade de alimentação e nutrição de um hospital universitário. Revista Medicina, v. 42, n. 4, p. 461-465, 2009.

PASSARONI, K. D. C. Manipuladores de alimentos: um fator de segurança alimentar. Monografia (Especialização) - Programa de Pós Graduação em Higiene e Inspeção de Produtos de Origem Animal, Universidade Castelo Branco, Brasília. 2006.

RIBEIRO, A.C.; REIS, D.O.; ROSSI, D.A. Procedimentos de higienização das mãos de manipuladores, em uma indústria frigorífica. Revista Higiene Alimentar, vol. 14, n. 70, p. 52 57, 2000.

SILVA JR, E.A. Manual de controle higiênicosanitário em serviços de alimentação. 6ed. São Paulo: Varela, 2007.

SILVA, L.F. Procedimento operacional padronizado de higienização como requisito para segurança alimentar em uma unidade de 
alimentação. Dissertação (Mestrado) - Programa de Pós Graduação em Ciência e Tecnologia de Alimentos, Universidade Federal de Santa Maria. 2006.

SILVA, N.; GERMANO, M.I.S.; GERMANO, P.M.L. Conhecimento dos manipuladores de merenda escolar em escolas da rede estadual de ensino em São Paulo, SP. Revista: Higiene Alimentar, v. 17, p. 46-51, 2003.

SOUZA, R.V. Manipuladores de alimentos: Um desafio para implementação da RDC 216/04. Monografia (Pós graduação) - Programa de Pós Graduação em Qualidade de Alimentos, Universidade de Brasília. 2006.

ZACCARELLI, E.M.; PHILIPPI, S.T. Avaliação de momentos de refeição em creches. Nutrire: Revista da Sociedade Brasileira Alimentar de Nutrição, São Paulo, v. 30, p. 17-29, 2005.

ZOCCHE, F. Staphylococcus aureus enterotoxigênicos: PCR para detecção em queijo minas frescal e caracterização do agrupamento egc em isolados obtidos em alimentos de origem animal. Tese (Doutorado) - Programa de Pós Graduação em Ciência e Tecnologia Agroindustrial, Universidade Federal de Pelotas. 2008. 